\title{
Sonographic Estimated Fetal Weight and Cesarean Delivery among Nulliparous Women with Obesity
}

\author{
Annie M. Dude, MD, PhD ${ }^{1} \quad$ Berkley Davis, MS ${ }^{2}$ Katie Delaney, MD² Lynn M. Yee, MD, MPH ${ }^{1}$ \\ ${ }^{1}$ Division of Maternal-Fetal Medicine, Department of Obstetrics and \\ Gynecology, Feinberg School of Medicine, Northwestern University, \\ Chicago, Illinois \\ 2 Feinberg School of Medicine, Northwestern University, Chicago, Illinois

\begin{abstract}
Address for correspondence Annie Dude, MD, Department of Obstetrics and Gynecology, Feinberg School of Medicine, Northwestern University, 250 East Superior Street, Suite 5-2185, Chicago, IL 60611 (e-mail: annie.dude@gmail.com).
\end{abstract}

Am J Perinatol Rep 2019;9:e127-e132.

\begin{abstract}
Keywords

- obesity

- pregnancy

- ultrasound

- cesarean section

- large for gestational age

Objective This study was aimed to examine the association between having an ultrasound estimate of fetal weight (US-EFW) and mode of delivery among obese women.

Study Design A retrospective cohort study of nulliparous women with a body mass index of $\geq 35 \mathrm{~kg} / \mathrm{m}^{2}$ who delivered term singleton gestations. We examined whether having had an US-EFW within 35 days of delivery, or an US-EFW $\geq 90$ th percentile for gestational age, was associated with intrapartum cesarean delivery.

Results Of 2,826 women, $22.5 \%(n=636)$ had an US-EFW within 35 days of delivery. Having an US-EFW was associated with increased frequency of cesarean (43.1\% for those with an US-EFW versus $30.0 \%$ for those without, $p<0.001$ ); this finding persisted when controlling for confounders (adjusted odds ratio [aOR] 1.48, 95\% confidence interval $[\mathrm{Cl}] 1.21-1.81$ ). Of the 636 women with an US-EFW, $22.5 \%$ $(n=143)$ had an US-EFW $\geq 90$ th percentile for gestational age, which was associated with increased frequency of an intrapartum cesarean $(60.8 \%$ for those with an USEFW $\geq 90$ th percentile vs. $37.9 \%$ for those with an US-EFW of $<90$ th percentile, $p<0.001$ ), even when accounting for confounders (aOR $=1.78,95 \% \mathrm{Cl}: 1.10-2.87$ ). Conclusion The presence of an US-EFW among nulliparous obese women was associated with undergoing intrapartum cesarean delivery.
\end{abstract}

Obstetricians use ultrasound to predict fetal weight near delivery. ${ }^{1}$ Obese women are more likely than nonobese women to undergo ultrasound in the third trimester because following fundal height is less feasible in this patient population. $^{2}$ Obesity is increasingly common in reproductive aged women $^{3}$; thus, the use of ultrasound in obese pregnant women will likely only increase.

Recent evidence indicates that obstetric providers may be influenced by ultrasound data when making decisions regarding mode of delivery. While some studies of lowrisk populations show that an ultrasound-estimated fetal weight (US-EFW) is not associated with increased risk of cesarean delivery, ${ }^{4}$ most others indicate that an US-EFW is associated with increased frequency of cesarean delivery, regardless of actual birth weight. ${ }^{5-7}$ The association between an US-EFW and cesarean is even stronger for fetuses estimated to be $\geq 90$ th percentile for gestational age, even though the sensitivity of ultrasound for an EFW $\geq 90$ th percentile is low. ${ }^{8-10}$ This body of literature suggests the performance of an US-EFW may influence provider cognitive processes independent of actual birth weight in ways that affect management of women during labor.

Understanding the potential influence of an US-EFW on mode of delivery is especially pertinent in light of the American College of Obstetricians and Gynecologists' (ACOGs') stated goal of reducing the rate of primary cesarean delivery, ${ }^{11}$ which is currently at an all-time high. ${ }^{12}$ Obese women are already at higher risk of cesarean delivery than received

November 19, 2018

accepted

February 21, 2019
DOI https://doi.org/

10.1055/s-0039-1684035. ISSN 2157-6998.
Copyright $\odot 2019$ by Thieme Medical Publishers, Inc., 333 Seventh Avenue, New York, NY 10001, USA. Tel: +1(212) 584-4662.
License terms

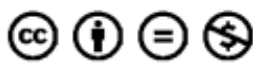


their nonobese counterparts, ${ }^{13}$ and when undergoing cesarean delivery experience complications, such as wound infections, at higher rates than nonobese women. ${ }^{14}$ The extent to which the presence of an US-EFW and ultrasonographic diagnosis of estimated fetal weight $\geq 90$ th percentile when an ultrasound is performed are associated with risk of cesarean delivery in this already high-risk population remains unknown, as most previous studies have focused on low risk women.

We hypothesize that there is an increased risk of cesarean delivery, as well as a cesarean delivery for an arrest disorder, associated with the presence of an US-EFW or of the ultrasonographic diagnosis of an EFW $\geq 90$ th percentile.

\section{Materials and Methods}

This is a retrospective cohort study of nulliparous women with a body mass index (BMI) at the time of delivery of $35 \mathrm{~kg} / \mathrm{m}^{2}$ or greater who delivered term ( $37^{0 / 7}$ weeks of gestation or greater), singleton gestations and received sonographic examinations at Northwestern Memorial Hospital in Chicago, IL, between January 1, 2010 and December 31, 2015. We chose women with a BMI of $35 \mathrm{~kg} / \mathrm{m}^{2}$ or greater at delivery as this represents the group of women who were most likely to have had a BMI of $30 \mathrm{~kg} / \mathrm{m}^{2}$ or more at the start of pregnancy, not just at delivery. Using this cut-off also allows us to focus on the group of women most likely to have undergone an ultrasound given inability to follow serial fundal heights. All women in this study underwent a trial of labor. We included women who presented in spontaneous labor as well as women who were induced. While women at our institution are often induced for medical comorbidities, such as chronic hypertension and diabetes, we do not routinely induce women for obesity alone. We excluded women who underwent primary cesarean delivery for presumed macrosomia, as this study was designed to assess how knowledge of estimated fetal weight might affect intrapartum management. We also excluded women who had a contraindication to a vaginal trial of labor, such as malpresentation, or who elected for a primary cesarean in the absence of labor. Finally, we excluded women with fetuses with major anomalies. Per standard clinical practice, pregnancies were initially dated by last menstrual period (LMP); pregnancies were dated or redated using ultrasound either when the LMP was unknown or when the dating by LMP conflicted with dating by ultrasound using standard ACOG guidelines. ${ }^{15}$

Clinical and demographic data were abstracted from the electronic medical record and ultrasound records used for clinical care. These data included whether a woman had any US-EFW in the last 5 weeks (up to 35 days) prior to delivery. We chose a cut-off of 5 weeks prior to delivery as previous studies have indicated that an ultrasound done at 34 to 36 weeks is reasonably predictive of birth weight at term in the population of pregnant women with obesity, ${ }^{16,17}$ and thus ultrasounds even 5 weeks prior to delivery are likely to be considered in physician decision making. Additionally, this time frame is felt to be pragmatic as clinicians do not always have a more recent ultrasound available. Ultrasounds performed in the eligible time period solely for fetal biophy- sical profile, position confirmation, or other reasons without performance of a growth estimate were not considered to have been an US-EFW.

Among women having an US-EFW, we defined women has having an EFW $\geq 90$ th percentile if the US-EFW was at or above the 90th percentile for gestational age at the time of ultrasound, based on the Hadlock's formula. ${ }^{18}$ We defined women as having a large-for-gestational age (LGA) neonate if the birth weight met or exceeded the 90th percentile for birth weight at a specific week of gestational age, using a standardized table of U.S. birth weights generated by Oken et. al. ${ }^{19}$

Our primary outcome was mode of delivery, categorized as vaginal delivery (including operative vaginal delivery) or cesarean delivery. Women were further classified as having undergone a cesarean for an arrest disorder if the primary indication for cesarean delivery was arrest of dilation, arrest of descent, or failed induction of labor.

Demographic and clinical variables potentially correlated with either obesity or cesarean delivery were abstracted from the medical record. These include class of obesity (class II, corresponding to a BMI of $35-39.9 \mathrm{~kg} / \mathrm{m}^{2}$, vs. class III, corresponding to a BMI of $\geq 40 \mathrm{~kg} / \mathrm{m}^{2}$ ), any maternal diabetes (gestational or pregestational), any hypertensive disorder of pregnancy (including chronic hypertension), maternal race/ethnicity (white non-Hispanic, black nonHispanic, Hispanic, Asian, or other), birth weight (measured in kilograms), maternal age at delivery (years), and induction of labor. Variables were retained in multivariable models if they were significantly associated with either cesarean delivery or having an US-EFW at the $p \leq 0.10$ level in bivariable comparisons.

The Student $t$-test or Chi-square analyses were used for continuous and categorical variables, respectively, in bivariable analyses. Multivariable logistic regression was used to control for potential confounders. Odds ratios (ORs) and 95\% confidence intervals (CIs) were estimated. All hypothesis tests were two-tailed, and a probability value of 0.05 was used to determine statistical significance. All analyses were performed in STATA (version 15.0, StataCorp, College Station, TX).

This protocol was approved by the Northwestern University Institutional Review Board (Protocol \# STU00202227) on $12 / 18 / 15$ with a waiver of informed consent.

\section{Results}

For this study, 3,001 women who met initial inclusion criteria were identified. Of these, 31 were excluded as they underwent a primary cesarean without labor for presumed macrosomia, 10 were excluded as they had a complete placenta previa, 111 were excluded for malpresentation, and 39 were excluded for other contraindications to vaginal delivery (including a previous cavity-entering myomectomy, active herpes simplex virus [HSV], and elevated human immunodeficiency virus [HIV] viral load). Five women underwent a nonmedically indicated primary cesarean delivery. Thirteen women were missing data on race/ethnicity and were also excluded; all other women had complete data on all potential confounders. Of the remaining 2,792 women with complete data who 
comprised the analyzable cohort, $22.6 \%$ ( $n=630$ ) had an USEFW within 5 weeks of delivery. Of those who had an ultrasound, $22.2 \%$ ( $n=140)$ had an antenatal diagnosis of USEFW $\geq 90$ th percentile for gestational age. Women were more likely to have had an US-EFW if they had any diabetes, hypertensive disorder, or a higher BMI. Additionally, women who underwent induction of labor were more likely to have an US-EFW (- Table 1).

In this cohort, $33.0 \%(n=922)$ underwent an intrapartum cesarean delivery. Having an US-EFW was associated with increased frequency of cesarean delivery: $42.9 \%(n=270)$ of the 630 women who had an US-EFW underwent cesarean versus $30.2 \%$ ( $n=652$ ) of 2,162 women who had no US-EFW $(p<0.001)$. This finding persisted even when controlling for actual birthweight and other confounding factors (adjusted OR $[\mathrm{aOR}]=1.36,95 \% \mathrm{Cl}$ : 1.12-1.67; - Table 2). Birthweight, induction of labor, any diabetes, black non-Hispanic race/ ethnicity, and maternal age were the other main demographic and clinical factors associated with increased odds of cesarean delivery ( - Table 2). Notably, maternal BMI itself was not associated with cesarean delivery once these other factors were accounted for.

An antenatal diagnosis of an US-EFW $\geq 90$ th percentile for gestational age was also associated with an increased frequency of cesarean delivery, with $60.7 \%(n=85)$ of the 140 women with an US-EFW $\geq 90$ th percentile for gestational age undergoing a cesarean, compared with $37.8 \%(n=185)$ of the 490 women with an US-EFW $<90$ th percentile $(p<0.001$; - Table 3). In multivariable models, an US-EFW $\geq$ 90th percentile for gestational age remained associated with increased odds of a cesarean delivery $(\mathrm{aOR}=1.82,95 \% \mathrm{CI}$ : 1.11-2.99) compared with having an US-EFW $<90$ th percentile. As - Table 1 shows, however, the diagnostic accuracy of ultrasound for LGA birth weight is not high; of 143 women with an US-EFW $\geq 90$ th percentile, only $43.6 \%(n=61)$ ultimately delivered a neonate that was large for gestational age. Birth weight, induction of labor, diabetes, and maternal age remained significantly associated with cesarean delivery.

Of the 922 women who underwent intrapartum cesarean delivery, $74.8 \%(n=690)$ had a cesarean delivery for an

Table 1 Cohort characteristics

\begin{tabular}{|c|c|c|c|c|c|c|}
\hline Variable & $\begin{array}{l}\text { US-EFW } \\
(n=630)\end{array}$ & $\begin{array}{l}\text { No US-EFW } \\
(n=2,162)\end{array}$ & $p$-Value & $\begin{array}{l}\text { US diagnosis } \\
\text { of } \geq 90 \text { th } \\
\text { percentile } \\
(n=140)\end{array}$ & $\begin{array}{l}\text { US diagnosis } \\
\text { of }<90 \text { th } \\
\text { percentile } \\
(n=490)\end{array}$ & $p$-Value \\
\hline Maternal age at delivery $(\mathrm{y})$ & $28.7 \pm 6.2^{c}$ & $29.1 \pm 6.2$ & 0.16 & $29.5 \pm 6.0$ & $28.5 \pm 6.3$ & 0.12 \\
\hline Maternal race: & & & $<0.001$ & & & 0.001 \\
\hline White non-Hispanic & $169(26.8)$ & $789(36.5)$ & & $57(40.7)$ & $112(22.9)$ & \\
\hline Black non-Hispanic & $192(30.5)$ & $377(17.4)$ & & $34(24.3)$ & $158(32.2)$ & \\
\hline Asian & $22(3.5)$ & $58(2.7)$ & & $5(3.6)$ & $17(3.5)$ & \\
\hline Hispanic & $152(24.1)$ & $591(27.3)$ & & $29(20.7)$ & $123(25.1)$ & \\
\hline Other & $95(15.1)$ & $347(16.1)$ & & $15(10.7)$ & $80(16.3)$ & \\
\hline $\begin{array}{l}\text { Maternal BMI at } \\
\text { delivery }\left(\mathrm{kg} / \mathrm{m}^{2}\right)\end{array}$ & $41.0 \pm 5.5$ & $39.5 \pm 4.8$ & $<0.001$ & $41.2 \pm 6.0$ & $40.9 \pm 5.3$ & 0.54 \\
\hline Class of obesity: & & & $<0.001$ & & & 0.62 \\
\hline Class II $\left(\mathrm{BMI}=35-39.9 \mathrm{~kg} / \mathrm{m}^{2}\right)$ & $331(52.5)$ & $1,464(67.7)$ & & $71(50.7)$ & $260(53.1)$ & \\
\hline Class III (BMI $\left.\geq 40 \mathrm{~kg} / \mathrm{m}^{2}\right)$ & $299(47.5)$ & $698(32.3)$ & & $69(49.3)$ & $230(46.9)$ & \\
\hline Any maternal diabetes & $111(17.6)$ & $109(5.0)$ & $<0.001$ & $27(19.3)$ & $84(17.1)$ & 0.56 \\
\hline $\begin{array}{l}\text { Any maternal } \\
\text { hypertensive disorder }\end{array}$ & $151(24.0)$ & $338(15.6)$ & $<0.001$ & $34(24.3)$ & $117(23.9)$ & 0.92 \\
\hline $\begin{array}{l}\text { Gestational age at } \\
\text { delivery (wk) }\end{array}$ & $39.4 \pm 1.2$ & $39.7 \pm 1.1$ & $<0.001$ & $39.7 \pm 1.2$ & $39.4 \pm 1.2$ & 0.01 \\
\hline Induction of labor & $329(52.2)$ & $750(34.7)$ & $<0.001$ & $76(54.3)$ & $253(51.6)$ & 0.58 \\
\hline Birth weight (kg) & $3.470 \pm 0.52$ & $3.466 \pm 0.46$ & 0.88 & $4.002 \pm 0.39$ & $3.318 \pm 0.45$ & $<0.001$ \\
\hline Birth weight category: & & & 0.05 & & & $<0.001$ \\
\hline SGA & $16(2.5)$ & $44(2.0)$ & & $0(0.0)$ & $16(3.3)$ & \\
\hline AGA & $529(84.0)$ & 1897 (87.7) & & $79(56.4)$ & $450(91.8)$ & \\
\hline LGA & 85 (13.5) & $221(10.2)$ & & $61(43.6)$ & $24(4.9)$ & \\
\hline
\end{tabular}

Abbreviations: AGA, appropriate gestational age; BMI, body mass index; LGA, large gestational age birth weight at delivery; SGA, small gestational age; US-EFW, ultrasonographic estimated fetal weight.

a Defined as US-EFW $\geq 90$ th percentile for gestational age at the time of ultrasound.

${ }^{\mathrm{b}}$ Defined as US-EFW $<90$ th percentile for gestational age at the time of ultrasound.

${ }^{c}$ Data presented are mean \pm standard deviation for continuous variables, $n(\%)$ for categorical variables. 
Table 2 A sonographic estimate of fetal weight is associated with cesarean delivery

\begin{tabular}{|c|c|c|c|c|c|}
\hline Variable & $\begin{array}{l}\text { Cesarean delivery } \\
(n=922)\end{array}$ & $\begin{array}{l}\text { Vaginal delivery } \\
(n=1,870)\end{array}$ & $p$-Value & $\begin{array}{l}\text { Adjusted } \\
\text { odds ratio }^{a}\end{array}$ & $\begin{array}{l}95 \% \text { confidence } \\
\text { interval }\end{array}$ \\
\hline Presence of an US-EFW ${ }^{b}$ & $270(29.3)^{c}$ & $360(19.3)$ & $<0.001$ & 1.36 & $1.12-1.67$ \\
\hline Birth weight (kg) & $3.600 \pm 0.50$ & $3.401 \pm 0.45$ & $<0.001$ & 2.63 & $2.18-3.17$ \\
\hline Induction of labor & $496(53.8)$ & $583(31.2)$ & $<0.001$ & 2.18 & $1.82-2.61$ \\
\hline Class of obesity: & - & - & $<0.001$ & - & - \\
\hline Class II (BMI $\left.{ }^{\mathrm{b}}=35-39.9 \mathrm{~kg} / \mathrm{m}^{2}\right)$ & $538(58.4)$ & $1,257(67.2)$ & & reference & - \\
\hline Class III (BMI $\left.\geq 40 \mathrm{~kg} / \mathrm{m}^{2}\right)$ & $384(41.7)$ & $613(32.8)$ & & 1.20 & $0.92-1.55$ \\
\hline Any maternal diabetes & $112(12.2)$ & $108(5.8)$ & $<0.001$ & 1.49 & $1.10-2.03$ \\
\hline Any maternal hypertensive disorder & $191(20.7)$ & $298(15.9)$ & 0.002 & 1.12 & - \\
\hline Maternal age at delivery (y) & $30.2 \pm 5.9$ & $28.5 \pm 6.2$ & $<0.001$ & 1.05 & $0.89-1.41$ \\
\hline Maternal race: & & & $<0.001$ & & $1.03-1.07$ \\
\hline White non-Hispanic & $319(34.6)$ & $639(34.2)$ & & (ref) & - \\
\hline Black non-Hispanic & $221(24.0)$ & $348(18.6)$ & & 1.84 & $1.42-2.38$ \\
\hline Asian & $28(3.0)$ & $52(2.8)$ & & 1.15 & $0.69-1.91$ \\
\hline Hispanic & 202 (21.9) & $541(28.9)$ & & 1.12 & $0.87-1.43$ \\
\hline Other & $152(16.5)$ & $290(15.5)$ & & 1.19 & $0.92-1.54$ \\
\hline Maternal BMI at delivery $\left(\mathrm{kg} / \mathrm{m}^{2}\right)$ & $40.4 \pm 5.2$ & $39.6 \pm 4.9$ & $<0.001$ & 1.00 & $0.98-1.03$ \\
\hline
\end{tabular}

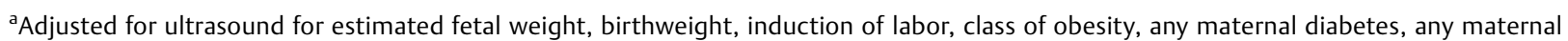
hypertensive disorder, maternal age, maternal race, maternal BMI.

bUS-EFW, ultrasonographic estimated fetal weight; BMI, body mass index.

${ }^{c}$ Data presented are mean \pm standard deviation for continuous variables, $n(\%)$ for categorical variables.

Table 3 Association between ultrasound diagnosis of estimated fetal weight $\geq 90$ th percentile and cesarean delivery

\begin{tabular}{|c|c|c|c|c|c|}
\hline Variable & $\begin{array}{l}\text { Cesarean delivery } \\
(n=270)\end{array}$ & $\begin{array}{l}\text { Vaginal delivery } \\
(n=360)\end{array}$ & $p$-Value & $\begin{array}{l}\text { Adjusted } \\
\text { odds ratio }^{a}\end{array}$ & $\begin{array}{l}95 \% \text { confidence } \\
\text { interval }\end{array}$ \\
\hline US diagnosis of $\geq 90$ th percentile ${ }^{b}$ & $85(31.5)^{c}$ & $55(15.3)$ & $<0.001$ & 1.82 & $1.11-2.99$ \\
\hline Birth weight (kg) & $3.584 \pm 0.50$ & $3.384 \pm 0.52$ & $<0.001$ & 1.87 & $1.23-2.84$ \\
\hline Induction of labor & $174(64.4)$ & $155(43.1)$ & $<0.001$ & 2.11 & $1.47-3.03$ \\
\hline Class of obesity: & & & 0.002 & & \\
\hline Class II (BMI $\left.=35-39.9 \mathrm{~kg} / \mathrm{m}^{2}\right)$ & $123(45.6)$ & $208(57.8)$ & & (ref) & \\
\hline Class III (BMI $\left.\geq 40 \mathrm{~kg} / \mathrm{m}^{2}\right)$ & $147(54.4)$ & $152(42.2)$ & & 1.19 & $0.70-2.01$ \\
\hline Any maternal diabetes & $69(25.6)$ & $42(11.7)$ & $<0.001$ & 2.14 & $1.34-3.43$ \\
\hline Any maternal hypertensive disorder & $72(26.7)$ & 79 (21.9) & 0.17 & 1.13 & $0.74-1.74$ \\
\hline Maternal age at delivery $(\mathrm{y})$ & $29.8 \pm 6.1$ & $27.9 \pm 6.1$ & 0.001 & 1.06 & $1.02-1.09$ \\
\hline Maternal race: & & & 0.33 & & \\
\hline White non-Hispanic & $77(28.5)$ & $92(25.6)$ & & (ref) & \\
\hline Black non-Hispanic & $89(33.0)$ & $103(28.6)$ & & 1.65 & $0.99-2.76$ \\
\hline Asian & $8(3.0)$ & $14(3.9)$ & & 0.71 & $0.26-1.99$ \\
\hline Hispanic & $55(20.4)$ & 97 (26.9) & & 0.93 & $0.54-1.61$ \\
\hline Other & $41(15.2)$ & $54(15.0)$ & & 1.11 & $0.63-1.93$ \\
\hline Maternal BMI at delivery $\left(\mathrm{kg} / \mathrm{m}^{2}\right)$ & $41.8 \pm 5.8$ & $40.4 \pm 5.2$ & 0.002 & 1.03 & $0.98-1.08$ \\
\hline
\end{tabular}

Abbreviation: BMI, body mass index.

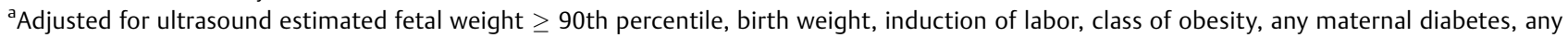
maternal hypertensive disorder, maternal age, maternal race, maternal BMI.

${ }^{b}$ Defined as ultrasonographic estimated fetal weight $\geq 90$ th percentile for gestational age at the time of ultrasound.

${ }^{c}$ Data presented are mean \pm standard deviation for continuous variables, $n(\%)$ for categorical variables. 
arrest disorder and 25.2\% $(n=232)$ had a cesarean delivery for fetal indications. Eliminating the 232 women who underwent cesarean for fetal indications, $30.4 \%(n=210)$ of the remaining 690 women who had a cesarean for an arrest disorder had an US-EFW, whereas only $19.3 \%(n=360)$ of the 1,870 women who underwent vaginal delivery had an US-EFW ( $p<0.001)$. When controlling for confounding factors, women who had an US-EFW were 1.46 times as likely to undergo a cesarean for arrest of dilation or descent (as opposed to a vaginal delivery) than women with no US-EFW (95\% CI: 1.17-1.82). Women with an US-EFW $\geq$ 90th percentile for gestational age were also more likely to undergo a cesarean for an arrest disorder; of the 210 women who underwent cesarean for an arrest disorder and had an US-EFW, $34.8 \%(n=73)$ had an US-EFW $\geq 90$ th percentile, whereas only $15.3 \%(n=55)$ of women who underwent vaginal delivery had an US-EFW $\geq 90$ th percentile $(p<0.001)$. This result did not, however, remain significant in multivariable models ( $\mathrm{aOR}=1.47$ for women who had an US-EFW $\geq$ 90th percentile, 95\% CI: 0.90-2.41).

\section{Discussion}

Many factors likely influence a practitioner's decisions regarding labor management and mode of delivery, including fetal status, maternal medical conditions, labor progress, and estimated fetal weight. In this study, among women with obesity undergoing a trial of labor, we found an association between the presence of an US-EFW within 5 weeks of delivery and cesarean delivery, even when accounting for actual birth weight. These findings are consistent with those of Froehlich et. al who studied a more general population regarding the association between documentation of an estimated fetal weight (clinical or ultrasonographic) and cesarean delivery. ${ }^{20}$ Our findings are also consistent with other studies among lower-risk women, 5,9 confirming that the presence of an ultrasound is associated with an increased intrapartum cesarean rate among this group of women already at higher risk for cesarean delivery. Although ACOG recommends consideration of cesarean delivery for women who have an US-EFW above $5,000 \mathrm{~g},{ }^{21}$ the women in this study did not meet this criterion and underwent cesarean delivery following a trial of labor.

Rather than US-EFW serving as a reason for a prelabor cesarean delivery, in this cohort of women who labored, we hypothesize the relationship between having an US-EFW and the performance of cesarean delivery is less straightforward. Previous work by our group indicated that obstetricians' cognitive traits are associated with their patients' mode of delivery. $^{22}$ In this same manner, perhaps the presence of an US-EFW subtly affects physicians' cognitive processes resulting in, for example, a lower threshold for cesarean delivery than in a comparable patient for whom US-EFW data were unavailable, for instance by giving the perception that the fetus was larger and may not fit in a woman's pelvis, even though the ultimate birth weight of all fetuses was similar. Such findings highlight the need to further understand the role of provider cognition and decision making in the context of having ultrasonographic data.
Our study suggested an US-EFW is associated specifically with a cesarean for an arrest disorder, as opposed to increased risk of cesarean delivery for nonreassuring fetal heart tracings, further bolstering the possibility that perceived knowledge of fetal weight may affect decisions providers make regarding how likely they feel their patients are to delivery vaginally. However, it was notable that the US-EFW had a poor ability to predict LGA status. Previous work on the accuracy of ultrasound to detect LGA fetuses has shown high specificity but low positive predictive value. ${ }^{9,23}$ In our study population, over half of the women identified as having an fetus with an EFW $\geq 90$ th percentile on ultrasound ultimately delivered an infant that was not LGA, demonstrating that ultrasound has a poor positive predictive value for fetal overgrowth; providers should keep this inherent inaccuracy in mind when making decisions regarding labor dystocia with regard to the US-EFW. As for all patients, one way to counteract a potentially misleading effect of an US-EFW on the cesarean rate is to adhere to standard definitions of labor dystocia. ${ }^{11}$

This paper has several strengths, including study of a large cohort of women with a BMI $\geq 35 \mathrm{~kg} / \mathrm{m}^{2}$ undergoing a trial of labor that included detailed information on the indication for cesarean delivery and offered the ability to determine the timing of an ultrasound relative to delivery. This diverse population was also cared for by a large number of clinicians, thus enhancing generalizability. Our work also has several limitations. First, performing an ultrasound to estimate fetal size was not universal, and there is no formal protocol at our institution regarding which women should be referred for a growth ultrasound. Rather, ultrasounds are ordered at the discretion of the main obstetric provider. Women who had an US-EFW were more likely to have a higher BMI, and thus selection bias in who received an US-EFW based on maternal BMI or another characteristic related to their baseline risk of a cesarean delivery may have confounded the association between provider knowledge of US-EFW and cesarean delivery. Similarly, we are able to control for some medical comorbidities, such as diabetes, which may influence which women received an ultrasound but not all medical comorbidities. Second, we used a 5-week cut-off for ultrasound prior to delivery given that, practically speaking, it is not possible to obtain an US-EFW for every patient within 1 to 2 weeks of delivery; however ultrasounds performed more distal to a patient's delivery may influence a practitioner's decision to perform a cesarean delivery in different ways than an US-EFW obtained closer to delivery might. Third, all patients at this institution are managed by both attending and trainee physicians, and thus it is not possible to distinguish whether there is a differential effect of provider experience. Providers are likely heterogenous in their propensity to perform a cesarean delivery based on experience and other factors that are not possible to measure. Finally, this is an observational study, and all associations are correlational.

While the results of this and other studies indicate that the use of ultrasound to estimate fetal weight is associated with an increase in odds of cesarean delivery, there remains a role for ultrasound in delivery planning. ${ }^{21}$ Ultrasound is also an important tool for diagnosing fetal growth disorders, such 
as intrauterine growth restriction, especially in populations where following fundal heights to screen for growth disorders is not likely to be accurate, such as in morbidly obese women. ${ }^{15}$ Further research could explore how providers use ultrasound information when counseling patients and managing patients in labor.

\section{Presentations}

A version of this paper was presented at the Society for Reproductive Investigation 65th Annual Scientific Meeting, March 6-10, 2018, San Diego, CA.

\section{Funding}

Author L.M.Y. is supported by the NICHD K12 HD05012111. Research reported in this publication was supported, in part, by the National Institutes of Health's National Center for Advancing Translational Sciences, Grant Number UL1TR001422. The content is solely the responsibility of the authors and does not necessarily represent the official views of the National Institutes of Health.

\section{Conflicts of Interest}

None of the authors have any conflicts of interest to report.

\section{References}

1 Siddique J, Lauderdale DS, VanderWeele TJ, Lantos JD. Trends in prenatal ultrasound use in the United States: 1995 to 2006. Med Care 2009;47(11):1129-1135

2 Gunatilake RP, Perlow JH. Obesity and pregnancy: clinical management of the obese gravida. Am J Obstet Gynecol 2011;204(02): 106-119

3 Fisher SC, Kim SY, Sharma AJ, Rochat R, Morrow B. Is obesity still increasing among pregnant women? Prepregnancy obesity trends in 20 states, 2003-2009. Prev Med 2013;56(06):372-378

4 Yee LM, Grobman WA. Relationship between third-trimester sonographic estimate of fetal weight and mode of delivery. J Ultrasound Med 2016;35(04):701-706

5 Little SE, Edlow AG, Thomas AM, Smith NA. Estimated fetal weight by ultrasound: a modifiable risk factor for cesarean delivery? Am J Obstet Gynecol 2012;207(04):309.e1-309.e6

6 Blackwell SC, Refuerzo J, Chadha R, Carreno CA. Overestimation of fetal weight by ultrasound: does it influence the likelihood of cesarean delivery for labor arrest? Am J Obstet Gynecol 2009;200 (03):340.e1-340.e3

7 Melamed N, Yogev Y, Meizner I, Mashiach R, Ben-Haroush A. Sonographic prediction of fetal macrosomia: the consequences of false diagnosis. J Ultrasound Med 2010;29(02):225-230
8 Matthews KC, Williamson J, Gupta S, et al. The effect of a sonographic estimated fetal weight on the risk of cesarean delivery in macrosomic and small for gestational-age infants. J Matern Fetal Neonatal Med 2017;30(10):1172-1176

9 Scifres CM, Feghali M, Dumont T, et al. Large-for-gestational-age ultrasound diagnosis and risk for cesarean delivery in women with gestational diabetes mellitus. Obstet Gynecol 2015;126(05):978-986

10 Parry S, Severs CP, Sehdev HM, Macones GA, White LM, Morgan MA. Ultrasonographic prediction of fetal macrosomia. Association with cesarean delivery. J Reprod Med 2000;45(01):17-22

11 Caughey AB, Cahill AG, Guise JM, Rouse DJ; American College of Obstetricians and Gynecologists (College); Society for MaternalFetal Medicine. Safe prevention of the primary cesarean delivery. Am J Obstet Gynecol 2014;210(03):179-193

12 Hamilton BE, Hoyert DL, Martin JA, Strobino DM, Guyer B. Annual summary of vital statistics: 2010-2011. Pediatrics 2013;131(03): 548-558

13 Gunatilake RP, Smrtka MP, Harris B, et al. Predictors of failed trial of labor among women with an extremely obese body mass index. Am J Obstet Gynecol 2013;209(06):562.e1-562.e5

14 Conner SN, Verticchio JC, Tuuli MG, Odibo AO, Macones GA, Cahill AG. Maternal obesity and risk of postcesarean wound complications. Am J Perinatol 2014;31(04):299-304

15 Committee on Practice Bulletins-Obstetrics and the American Institute of Ultrasound in Medicine. Practice bulletin no. 175: ultrasound in pregnancy. Obstet Gynecol 2016;128(06):e241-e256

16 Ahmadzia HK, Thomas SM, Dude AM, Grotegut CA, Boyd BK. Prediction of birthweight from third-trimester ultrasound in morbidly obese women. Am J Obstet Gynecol 2014;211(04):431.e1-431.e7

17 Thornburg LL, Barnes C, Glantz JC, Pressman EK. Sonographic birthweight prediction in obese patients using the gestation-adjusted prediction method. Ultrasound Obstet Gynecol 2008;32(01):66-70

18 Hadlock FP, Harrist RB, Martinez-Poyer J. In utero analysis of fetal growth: a sonographic weight standard. Radiology 1991;181(01): 129-133

19 Oken E, Kleinman KP, Rich-Edwards J, Gillman MW. A nearly continuous measure of birth weight for gestational age using a United States national reference. BMC Pediatr 2003;3:6

20 Froehlich RJ, Sandoval G, Bailit JL, et al; MSCE, for the Eunice Kennedy Shriver National Institute of Child Health and Human Development (NICHD) Maternal-Fetal Medicine Units (MFMU) Network. Association of recorded estimated fetal weight and cesarean delivery in attempted vaginal delivery at term. Obstet Gynecol 2016;128(03):487-494

21 American College of Obstetricians and Gynecologists' Committee on Practice Bulletins-Obstetrics. Practice bulletin no. 173: fetal macrosomia. Obstet Gynecol 2016;128(05):e195-e209

22 Yee LM, Liu LY, Grobman WA. The relationship between obstetricians' cognitive and affective traits and their patients' delivery outcomes. Am J Obstet Gynecol 2014;211(06):692.e1-692.e6

23 Valent AM, Newman T, Kritzer S, Magner K, Warshak CR. Accuracy of sonographically estimated fetal weight near delivery in pregnancies complicated with diabetes mellitus. J Ultrasound Med 2017;36(03):593-599 